\title{
CANINE ANGULATION AND ROTATION DURING CANINE RETRACTION USING ELASTOMERIC CHAINS WITH AND WITHOUT A POWER ARM
}

\author{
Hend S. ElSayed ${ }^{*}$, Reem Alshazly ${ }^{* *}$, Amr R. El-Beialy ${ }^{* * *}$ and Fouad A. El Sharaby ${ }^{* * *}$
}

\begin{abstract}
Background: During canine retraction, orthodontic forces are applied away from the tooth's center of resistance. This introduces canine distal tipping and mesiobuccal rotation. The correction of these unwanted movements will prolong treatment time. Applying the force closer to the center of resistance should decrease this unwanted tooth movement.
\end{abstract}

Objective: Compare the canine angulation and rotation during canine retraction with and without the use of power arm.

Materials and Methods: Twenty-four female orthodontic patients (age 19.32 4.17 years) with dental Class II indicated for bilateral maxillary first premolar extraction and maximum anchorage were included in this study. The canines were retracted with elastomeric chains over $0.017 \times 0.025$ " statinless steel arch wires to reduce friction. The retraction force was $150 \mathrm{~g}$. In twelve patients, the canines were retracted using a power arm fixed to the vertical slots of the canine brackets. For the other twelve patients, the elastic chains were attached to the bracket hooks.

Results: Before treatment, the canine angulation and rotation was similar for the two groups. The canine angulation was $12.38 \pm 8.27$ and $14.5^{\circ} \pm 9.41$ for the group with the power arm and without, respectively. while canine rotation was $64.74^{\circ} \pm 11.65$ and $63.12^{\circ} \pm 14.88$, respectively. Post-retraction, there was no significant difference in the canine angulation or rotation between the groups.

Conclusion: Compared to canine retraction with a power arm, conventional canine retraction with elastomeric chains attached to the bracket hook may provide similar control over distal tipping, provided a stiff 0.017 " X 0.025 " stainless steel arch wire is used.

KEYWORDS: Canine retraction, power arm, canine angulation, canine rotation

* Associate Professor, Department of Orthodontics \& Pediatric Dentistry, Oral and Dental Research Division, National Research Centre, Giza, Egypt \& Adjunct Assistant Professor, Department of Epidemiology \& Health Promotion, College of Dentistry, NYU.

** Assistant lecturer, Department of Orthodontics and Dentofacial Orthopedics, Faculty of Oral \& Dental Medicine, Future University in Egypt, Cairo, Egypt.

*** Associate Professor, Department of Orthodontics and Dentofacial Orthopedics, Faculty of Dentistry, Cairo University, Cairo, Egypt. 


\section{INTRODUCTION}

Frequently, orthodontic patients require first premolar extraction to relief arch-length to tooth-size discrepancy. With friction mechanics, the canine is retracted along the orthodontic archwire to close the extraction space. The distal force is applied labially or lingually to the long axis of the tooth and at the level of the bracket away from the tooth's center of resistance. This produces rotational moments causing a distal-in canine rotation and distal crown tip. ${ }^{[1]} \mathrm{A}$ rigid arch wire and tight ligature wire can produce a counter moment to set off the rotational couple produced by the distal force. However, the flexibility of the arch wire and ligature ties as well as the arch wire-bracket slot play will always allow a degree of canine rotation and tipping.

The use of a power arm extending gingivally towards the tooth's center of resistance, as a point of force application, will reduce distal tipping as recommended by Ansari based on a finite element study ${ }^{[2]}$ Similarly, AlKebsi et a ${ }^{[3]}$ reported clinically insignificant amounts of canine tipping and rotation when the canines were retracted using power arms.

The aim of this study was to compare the canine angulation and rotation during canine retraction using elastomeric chains with and without a power arm.

\section{Methodology}

This is a retrospective cohort study where the records of patients treated in the Orthodontic Department at FUE were analyzed. The study method was approved by the Institutional Review Board of Faculty of Dentistry, Future University in Egypt. Twenty-four quadrants in twelve female patients with Class II malocclusion had recently completed canine retraction. Their mean age at the start of retraction was $19.32 \pm 4.17$ years. All patients were indicated for bilateral maxillary first premolar extraction and required maximum anchorage. All patients were fitted bonded with conventional Roth prescription brackets. Levelling and alignment were completed. Canines were retracted, in twenty-four maxillary quadrants, using elastomeric chains (American Orthodontics, USA). The canines were retracted over $0.017 \times 0.025$ " stainless steel archwires. The elastic chain was attached to a miniscrew (3M Unitek TAD, St. Paul, Minn., 8 by $1.6 \mathrm{~mm}$ ), placed between the second premolar and first maxillary molar, and a power arm at the canine bracket. The power arms were formed of $0.016 " \mathrm{X} 0.022$ " stainless steel wires and were $8 \mathrm{~mm}$ in height. They were secured in the vertical slot of the canine bracket using flowable light-cured composite. The retracion force was $150 \mathrm{~g}$, verified with a force gauge (The elastic chains were replaced every 4 weeks) (Fig. 1).

These patients were matched to twelve other patients with the same criteria, sex and age from the clinic records, who were receiving orthodontic treatment during the same time period (May 2018 to April 2019). The maxillary canines in the matched patients were retracted with the same methodology except the canines were retracted over a 0.017 " $\mathrm{X} 0.025 "$ arch wire and the elastic chains were stretched between the miniscrew and the hook of the canine bracket instead of a power arm.

Pre-treatment and post-retraction cone beam computer tomograms were available for all the patients. The Invivo Dental 5 software (version 5.3.1, Company, Santa Clara, Calif.) was used to

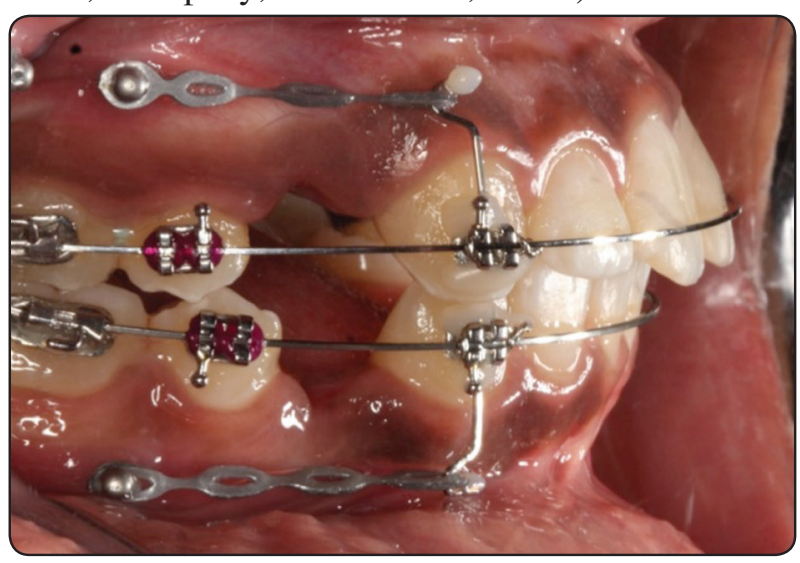

Fig. (1): Retraction of a maxillary canine using an elastomeric chain extended between a power arm at the canine bracket and miniscrew. 


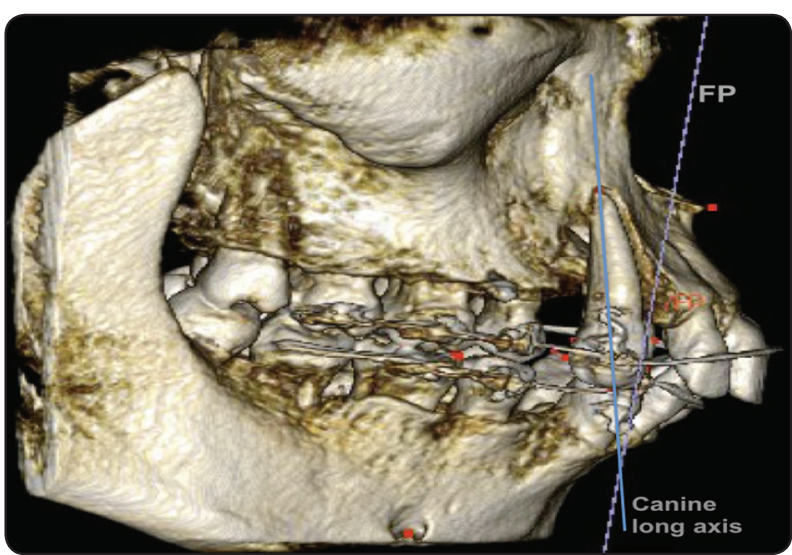

Fig. (2): The Frontal Plane (FP); reference plane passing through the incisive foramen and the canine long axis; cusp tip to root apex.

import the digital imaging and communications in medicine images and to construct the 3D images. The frontal plane was constructed orthogonally to the mid-sagittal and horizontal planes. (Fig. 2) Canine angulation was measured as the angle between the long axis of the canine, from cusp tip to root apex, and the frontal plane. The canine rotation was measured as the Canine rotation measured as the outer angle between a line connecting the mesial and distal contact points of the canine crown and the frontal plane. (Fig. 3)

\section{Statistical analysis}

The data for the canine angulation and rotation in each group was evaluated for normality using the

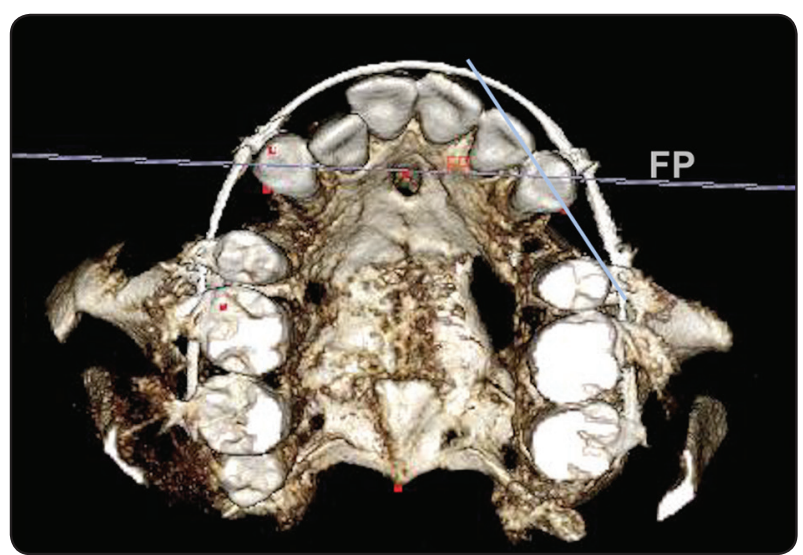

Fig. (3): Canine rotation measured as the outer angle between a line connecting the mesial and distal contact points of the canine crown and the Frontal Plane (FP).

Kolmogorov-Smirnov test. The power arm and no power arm groups were compared before the start of treatment and at the end of canine retraction for canine angulation and rotation using the t-test. All tests were set at $95 \%$ confidence level.

\section{RESULTS}

Fourty-eight quadrants, 24 in each group, were analyzed. The data showed normal distribution. The power arm and no power arm groups showed no statistical difference for canine angulation and rotation at the start of treatment. (Table 1) There was no statistical difference between the two groups for canine angulation or rotation (Table 2)

TABLE (1) Baseline descriptive statistics of canine angulation and rotation for the power arm and no power arm groups.

\begin{tabular}{lcccc}
\hline & $\begin{array}{c}\text { Canine retraction with power } \\
\text { arm } n=24\end{array}$ & $\begin{array}{c}\text { Canine retraction without power } \\
\text { arm } n=24\end{array}$ & $\mathrm{t}$ & $\mathrm{p}$-value \\
\hline Canine angulation $\left(^{\circ}\right)$ & $22.62 \pm 8.82$ & $23.88 \pm 7.94$ & -0.5198 & 0.6057 \\
Canine rotation $\left(^{\circ}\right)$ & $43.17 \pm 13.52$ & $50.81 \pm 13.65$ & -1.9898 & 0.0526 \\
\hline
\end{tabular}

TABLE (2) Descriptive statistics and comparison of post-retraction canine angulation and rotation for the power arm and no power arm groups.

\begin{tabular}{lccccc}
\hline & $\begin{array}{c}\text { Canine retraction with } \\
\text { power arm }(\mathrm{n}=24)\end{array}$ & $\begin{array}{c}\text { Canine retraction without } \\
\text { power arm }(\mathrm{n}=24)\end{array}$ & $\mathrm{t}$ & $\begin{array}{c}\text { 95\% confidence } \\
\text { interval }\end{array}$ & p-value \\
\hline Canine angulation $\left({ }^{\circ}\right)$ & $12.38 \pm 8.27$ & $14.5 \pm 9.41$ & -0.8290 & $-12.7878,2.8920$ & 0.4114 \\
Canine rotation $\left({ }^{\circ}\right)$ & $64.74 \pm 11.65$ & $63.12 \pm 14.88$ & -0.4205 & $-7.1320,9.1807$ & 0.6761 \\
\hline
\end{tabular}




\section{DISCUSSION}

The correction of canine distal tipping and rotation after canine retraction can be a timeconsuming process. Shpack et a ${ }^{[4]}$ showed that bodily movement reduced the time of canine retraction by 28 days in comparison to tipping followed by canine uprighting. While Daskalogiannakis and McLachlan $^{[5]}$ showed no significant difference in canine tipping and rotation when continuous or interrupted forces were applied. However, Mezomo et $\mathrm{al}^{[6]}$ reported that upper canines rotation was minimized with self-ligating compared to conventional brackets.

Nanda $^{[7]}$ described four phases of sliding mechanics. At first the archwire-bracket play produces uncontrolled tipping. Therefore, the use of arch wires of greater dimension can reduce tipping. The second phase occurs with the initial contact between the bracket slot and the arch wire, which produces a rotational couple leading to controlled tipping. If the arch wire is flexible, deformation will occur negating the moment. In Phase III, the moment to force ratio increases leading to translation movement. Finally, the moment of the couple exceeds that of the force leading to root uprighting. Thus, canine tipping may be reduced by allowing sufficient time for bodily movement and root uprighting.

Ziegler and Ingervall ${ }^{[8]}$ and Rhee et a ${ }^{[9]}$ reported that frictionless mechanics was more efficient in reducing canine tipping than sliding mechanics when retracting maxillary canines. The canines were retracted with less distal tipping with the spring $\left(0.8^{\circ} / \mathrm{mm}\right)$ than with sliding mechanics $(1.4 /$ $\mathrm{mm})$. In comparison, Hayashi ${ }^{[10]}$ et al reported $7.94^{\circ}$ tipping after only 2 months of canine retraction.

Hayashi et al ${ }^{[10]}$ and Rhee et al ${ }^{[9]}$ showed some evidence that sliding mechanics provide better control over canine rotation than retraction springs. Hayashi et $\mathrm{el}^{[10]}$ reported a five times more rotation with retraction spring $\left(22.06^{\circ}\right)$ compared to $4.07^{\circ}$ in sliding mechanics, in two month of retraction. The rotation found in the present study was similar to that reported by Mezomo et $\mathrm{al}^{[6]}\left(12.2^{\circ}\right)$ with conventional brackets. However, Ziegler and Ingervall $^{[8]}$ showed similar amounts of canine rotation for $6 \mathrm{~mm}$ of retraction in sliding mechanics $\left(24^{\circ}\right)$ and frictionless mechanics $\left(20^{\circ}\right)$.

Clinically, the position of the power arms prevented a tight fit of the ligature wires over the canine brackets. Yet, the results did not show an increase in the canine rotation for the group retracted with power arms. To overcome the rotational moments and reduce canine rotation during canine retraction, the use of stiff arch wires, V-bends and tight bracket ligation is recommended.

Two studies used similar biomechanics to that applied in our study. Cousley ${ }^{[11]}$ retracted the canines using mini implants and a bonded power arm. After retraction the angulation was measured with a panoramic radiograph. The author reports no change in the initial angulation indicating control over the distal tipping. However, this data was reported for only two patients. The second study was a split-mouth randomized controlled trial conducted by Akın and Camc1. ${ }^{[12]}$ The authors retract the canines using mini-implants as indirect anchorage for the first permanent molars. The elastomeric chains were stretched between the molars and power arms. The height of the power arm was determined in a similar manner to that used in our study. The length was extended to the coronal third of the root. Their results are similar to ours. Canine tipping was similar with $\left(3.62^{\circ} \pm 2.91\right)$ and without the power arms $\left(4.82^{\circ} \pm 3.08\right)$. Rotation was $7.57^{\circ} \pm 4.70$ and $8.49^{\circ} \pm 5.25$ in the power arm and no power arm groups, respectively. The amounts of canine angulation and rotation was measured for the first 3 months. Had the trial continued until complete canine retraction, the tipping and rotation may have been as high as those reported in our study which lasted until canine retraction was completed. 
The amount of tipping is relatively controlled in this study despite that the power arm may not be the cause. It may be attributed to the 0.017 " $\mathrm{X}$ 0.025 " stainless steel arch wire. According to the results of a systematic review conducted by Barlow and Kula, ${ }^{[13\}}$ arch wires with larger dimensions had better control over tipping.

\section{CONCLUSION}

Within the limitations of this study and the inherent bias of retrospective studies, canine angulation and rotation were similar with and without the use of a power arm. Shpack et $\mathrm{al}^{[4]}$ showed similar results where bodily and tipping movements did not affect the degree of the canine rotation. Further well controlled studies should further investigate the effect of power arms on the canine tipping and rotation.

\section{REFERENCES}

1. Nikolai, R. J. On optimum orthodontic force theory as applied to canine retraction. Am J Orthod. 1975; 68: 290-302.

2. Ansari TA, Mascarenhas R, Husain A, Salim M. Evaluation of the power arm in bringing about bodily movement using finite element analysis. Orthodontics 2011;12: 318-329.

3. Alkebsi A, Al-Maaitah E, Al-Shorman H, Abu Alhaija E. Three-dimensional assessment of the effect of microosteoperforations on the rate of tooth movement during canine retraction in adults with Class II malocclusion: A randomized controlled clinical trial. Am J Orthod Dentofacial Orthop. 2018;153:771-85.

4. Shpack N, Davidovitch M, Sarne O, Panayi N, Vardimon AD. Duration and anchorage management of canine retraction with bodily versus tipping mechanics. Angle Orthod. 2008;78(1):95-100
5. Daskalogiannakis J, McLachlan KR. Canine retraction with rare earth magnets: An investigation into the validity of the constant force hypothesis. Am J Orthod Dentofac Orthop. 1996;109(5):489-495.

6. Mezomo M, de Lima ES, de Menezes LM, Weissheimer A, Allgayer S. Maxillary canine retraction with self-ligating and conventional brackets. Angle Orthod. 2011;81(2):292297.

7. Nanda R. Esthetics and Biomechanics in Orthodontics. $2^{\text {nd }}$ ed. ElSevier, Saunders; St Louis, Missouri, 2015. P. $108-120$

8. Ziegler P, Ingervall B. A clinical study of maxillary canine retraction with a retraction spring and with sliding mechanics. Am J Orthod Dentofacial Orthop. 1989;95(2):99-106.

9. Rhee J-N, Chun Y-S, Row J. A comparison between friction and frictionless mechanics with a new typodont simulation system. Am J Orthod Dentofac Orthop. 2001;119(3): 292-299.

10. Hayashi K, Uechi J, Murata M, Mizoguchi I. Comparison of maxillary canine retraction with sliding mechanics and a retraction spring: a three-dimensional analysis based on a midpalatal orthodontic implant. Eur J Orthod. 2004; 26(6):585-589.

11. Cousley R. Controlled canine retraction using orthodontic mini-implants coupled with bondable powerarms. J Orthod. 2015;42(4):315-323.

12. Akın Ş, and Camcı H. Three-dimensional assessment of two different canine retraction techniques: a randomized split-mouth clinical trial. Progress Orthod. 2021; 22:24

13. Barlow M, Kula K. Factors influencing efficiency of sliding mechanics to close extraction space : a systematic review. Orthod Craniofac Res. 2008;11:65-73. 